\title{
Gobernanza ambiental en Boyacá: un análisis «glocal»*
}

\author{
Walter Fernando Pérez-Niño \\ Docente investigador Universidad Libre - Sede Candelaria, Bogotá - Colombia \\ walter.perez@unilibre.edu.co (1) https://orcid.org/0000-0002-5924-235X \\ Wilmer Yesid Leguizamón-Arias \\ Docente de la Fundación Universitaria Juan de Castellanos, Tunja - Colombia \\ wyleguizamon@jdc.edu.co (D) https://orcid.org/0000-0003-1596-0277
}

RES U M N

En Colombia se han asumido modelos de desarrollo sustentados en la extracción de materias primas, provocando con ello, múltiples conflictos socioambientales entre los distintos actores sociales y el Estado. En este contexto, la implementación de mecanismos de gobernanza ambiental ha permitido consolidar herramientas de resistencia a la idea global de desarrollo económico a partir de la crítica y, eventual rechazo, de las comunidades y colectividades afectadas por la ejecución de proyectos extractivos. El presente artículo, explora los diferentes procesos de gobernanza ambiental adelantados en el Departamento de Boyacá, a través de una metodología interdisciplinar que involucra, el estudio socioambiental y el análisis jurídico, por medio de instrumentos cualitativos, que permiten entender de manera "glocal" (local y global) las dimensiones reales del problema y las iniciativas sociales exitosas para su solución en el Departamento.

Palabras clave

Extractivismo; gobernanza ambiental; conflicto ambiental; glocalismos

\section{Environmental governance and social movements in Boyacá department: an analysis in glocal perspective}

A B S T R A C T

In Colombia, development models based on the extraction of raw materials have been assumed, thereby causing multiple socioenvironmental conflicts between the different social actors and the State. In this context, the implementation of environmental governance mechanisms has consolidated tools of resistance to the global idea of economic development based on criticism and, eventually, rejection of the communities and communities affected by the execution of extractive projects. This article explores the different processes of environmental governance carried out in the Department of Boyacá, through an interdisciplinary methodology that involves the socio-environmental study and legal analysis, through qualitative instruments, which allows us to understand "glocally" "(local and global) the real dimensions of the problem and the successful social initiatives for its solution in the Department.

KEYWORDS

Extractivism; environmental governance; environmental conflict; glocalism

Recibido: 26/II/2019 Aceptado: 30/04/2020

* El artículo es un resultado de investigación dentro del proyecto: "Gobernanza ambiental y movimientos sociales: casos de defensa del bosque alto andino en Boyacá". El autor Walter Perez elabora este aporte como resultado de investigación del proyecto "Trabajadores de la cultura: Entre maestros, artistas, artesanos y deportistas.

Garantía de los derechos sociales en Colombia".

Este es un artículo Open Access bajo la licencia BY-NC-SA (http://creativecommons.org/licenses/by-nc-sa/4.0/)

Cómo citar este artículo: PÉREZ-NIÑO, Walter Fernando; LEGUIZAMÓN-ARIAS, Wilmer Yesid. Gobernanza ambiental en Boyacá: un análisis «glocal». En: Entramado. Julio - Diciembre, 2020 vol. 16, no. 2, p. 202-218 https://doi.org/l0.1804//1900-3803/entramado.2.6662 


\section{Governança ambiental em Boyacá: uma análise "glocal"}

Na Colômbia, assumiram-se modelos de desenvolvimento baseados na extração de matérias-primas, gerando múltiplos conflitos socioambientais entre os diversos atores sociais e o Estado. Neste contexto, a implementação de mecanismos de governança ambiental tem permitido consolidar ferramentas de resistência à ideia global de desenvolvimento econômico baseado na crítica e, eventual rejeição, das comunidades e coletivos afetados pela execução de projetos extrativistas. Este artigo explora os diferentes processos de governança ambiental realizados no Departamento de Boyacá, por meio de uma metodologia interdisciplinar que envolve estudo socioambiental e análise jurídica, por meio de instrumentos qualitativos, que nos permitem compreender de forma "glocal" (local e global) as reais dimensões do problema e as iniciativas sociais bem-sucedidas para sua solução no Departamento.

Palavras-chave

Extrativismo; governança ambiental; conflito ambiental; glocalismos

\section{Introducción}

El orden económico global ha establecido roles en las cadenas de producción internacionales. En ese escenario, Colombia asumió el papel de proveedor masivo de materias primas como el petróleo, el carbón y el oro, acogiendo el modelo extractivista, que en palabras de Gudynas es el proceso de explotación de recursos naturales a escala industrial con destino al mercado internacional (2013, p.9), en sus distintas versiones (extractivismo convencional' y neoextractivismo) ${ }^{2}$ (Portillo, 20|4, p.|5). El extractivismo aplicado en los territorios de manera masiva ha generado conflictos entre gobiernos, empresarios, ONG's, movimientos sociales y demás actores, por lo que es preciso revisar las dinámicas locales y globales que se desarrollan en medio de las tensiones.

Teniendo en cuenta lo anterior, se pueden observar al menos dos principios de conflicto. El primero se deriva de las tensiones socioambientales particularmente "glocales", de tal manera, se adelantan procesos territoriales de defensa y protección del ambiente que, en algunas ocasiones, se fundamentan en concepciones que rechazan la versión hegemónica de desarrollo sostenible, presente en las políticas económicas promotoras del extractivismo. Este es un ejemplo de relación entre lo local y lo global, donde la globalización se localiza espacial y temporalmente (Robertson, 1995), produciendo conflictos en torno a la destinación de los recursos naturales. El segundo, se suscribe a ciertas, dinámicas promovidas por las comunidades y organizaciones sociales, que riñen con los procesos de globalización jurídica y economía general del país. Estos factores de conflictividad, explican la correlación entre decisiones locales que han privilegiado la protección de los ecosistemas estratégicos y los eventuales efectos de estas decisiones en el concierto internacional, como las demandas emprendidas por trasnacionales vinculadas a la explotación de recursos naturales, por eventuales incumplimientos de los tratados de promoción y protección de la inversión extranjera (Echaide, 2016).

Esos contextos de conflictividades sobre el manejo de la política ambiental también han generado el reto de establecer mecanismos para su solución. En este sentido, la gobernanza, y en concreto la gobernanza ambiental, surge como una propuesta para la gestión de los conflictos ambientales a través de la participación de las comunidades, el Estado y demás actores, en la búsqueda de concertación de las políticas públicas ambientales dentro de un proceso que impulsa y fortalece la participación democrática (Mayntz, 2002; Alfie Cohen, 2013).

Por las razones expuestas resulta pertinente analizar, bajo un enfoque "glocal", algunos de los procesos de gobernanza ambiental promovidos por los movimientos sociales como respuesta a la política extractiva. En el artículo, se toman como ejemplo los estudios de casos específicos, en el marco de los conflictos del Páramo de Pisba y el Páramo Tota - Bijagual - Mamapacha, ubicados en el departamento de Boyacá, con el propósito de analizar cómo se establece y desarrolla el proceso glocal en relación con la gobernanza ambiental permitiendo establecer algunas conclusiones acerca de la aplicación de dichos conceptos en contextos reales.

Para desarrollar el objetivo propuesto, el artículo está estructurado de la siguiente manera: el primer apartado presenta una aproximación al fenómeno de extracción a escala industrial de recursos naturales que en el mercado se denominan "commodities" y la reacción de la ciudadanía frente a los diversos daños ambientales derivados de esta actividad. En este contexto, se abordan las diferentes 
acepciones del concepto de gobernanza ambiental y algunas de sus categorías, que permitirán comprender de mejor manera los casos de estudio en el Departamento de Boyacá.

En el segundo apartado se realiza una presentación de las conflictividades socioambientales del departamento de Boyacá ${ }^{3}$, haciendo una descripción general de los ecosistemas y en particular examinando las problemáticas asociadas con hidrocarburos y minería, para lo cual se examinan algunos resultados cuantitativos ya procesados, sobre el respecto.

En tercer lugar, se aborda el estudio de caso del páramo de Pisba y Tota - Bijagual- Mamapacha, desde la perspectiva glocal, como criterio de análisis que permitirá entender la dimensión de las fuerzas que enfrentan las comunidades en sus procesos de gobernanza ambiental.

Desde el punto de vista metodológico se desarrolla una perspectiva analítica a partir de la investigación socioambiental que es pertinente para el estudio integral de los procesos de cambio, así como las cuestiones y tensiones derivadas de la concepción de desarrollo (Castro, Hogenboon y Baud, 2015). Asimismo, se introducen diversos elementos de carácter interdisciplinar, como el análisis sociológico para comprender las dinámicas de los conflictos socioambientales suscitados por la intervención minera, el análisis jurídico y el uso de instrumentos cualitativos para dimensionar las conflictividades socioambientales. También se acude al estudio de caso, siendo pertinente porque permite acudir a todo tipo de fuentes tanto cualitativas como cuantitativas (Martínez Carazo, 2006)

\section{Extractivismo y Gobernanza ambiental}

El medio ambiente ha sufrido constantemente la acción depredadora del ser humano. La producción y el consumo se ha exacerbado, y con ello, secuelas nocivas como la contaminación, producida especialmente por la extracción de materias primas - o commodities -, así como la fabricación de bienes secundarios y la gestión inadecuada de los residuos. Las necesidades de crecimiento económico sobrepasan la capacidad del mundo para satisfacerlas, por lo tanto, no son sostenibles ambientalmente. Este impacto, repercute negativamente no solo en el planeta sino en quienes lo habitan (Asara, Otero, Demaria y Corbera, 20I5). Estamos en un punto de no retorno, en el que es cada vez más evidente el desequilibrio junto a todos sus efectos ambientales negativos. El ejemplo más claro de esto es el cambio climático y sus fenómenos asociados -inundaciones, sequias, descongelamiento de glaciares, etc.-.

Para la producción de bienes se ha establecido una serie de 204 económica principal la extracción de commodities, otros en cambio, se dedican a importar materias primas para transformarlas y venderlas. Generalmente los países con bajos niveles de desarrollo, como los de América Latina ${ }^{4}$, se acogen al modelo extractivista. Es decir, no solamente el Estado permite la apropiación masiva de los recursos naturales para su explotación (Gudynas, 2015; Gudynas, 2014) sino que se confía la economía nacional, a las ganancias recibidas por esta actividad ${ }^{5}$ que redunda en el beneficio de los países que requieren y transforman este tipo de insumos como Estados Unidos y China (Gamba, Fuentes y Contreras, 20I2). Las cifras indican que el $70 \%$ del total de las exportaciones de los países latinoamericanos y del Caribe corresponden a este tipo de bienes (PérezRincón, 2016).

Colombia, por su parte $y$ al no tener un nivel de industrialización importante, ha implementado un modelo económico extractivista. A lo largo de distintos gobiernos, se han mantenido políticas basadas en un discurso del desarrollo económico a partir del modelo extractivista. Entre 1990 y 2014 las exportaciones del país aumentaron de $12 \mathrm{I}$ mil millones de dólares a $960 \mathrm{mil}$, que corresponde a un crecimiento de 838 mil millones. De este incremento, el $49 \%$ hace parte del sector primario y manufacturas basadas en recursos naturales (Pérez-Rincón, 2016).

Diferentes estudios apuntan a que, este tipo de explotación de bienes primarios implica una serie de problemas derivados de la falta de planeación y control técnico y político de los procesos, tales como la contaminación ambiental, el riesgo sanitario, la pobreza y la desigualdad social. En todas las naciones, por regla general, las personas sin recursos económicos y las minorías afrontan mayores riesgos en relación con los efectos nocivos, provocados al ambiente por diferentes causas. Por otra parte, las decisiones sobre el uso y el subsecuente beneficio económico que se obtiene de la explotación de los recursos naturales, generalmente son impuestas, sin un estudio previo que señale las consecuencias sociales y ambientales o los posibles riesgos que deben asumir las comunidades afectadas ${ }^{6}$ (ShraderFrechette, 2002).

La actividad extractiva en terrenos mayormente rurales con el propósito de extraer los recursos naturales ha impactado de manera desfavorable, no solo al ambiente, sino a las comunidades incidiendo directamente en cambios abruptos en su forma de vida sus costumbres, $y$ la manera de relacionarse con la tierra. Los denominados "conflictos ambientales" son la manifestación de contradicciones que se presentan entre distintos actores como comunidades, Estados y compañías, respecto de las actividades que modifican las dinámicas históricas relacionadas con el uso del ambiente y sus impactos en la sociedad. La movilización 
y la protesta se han empleado como herramientas efectivas en la manifestación de las inconformidades de los sectores y comunidades afectadas por las nuevas dinámicas (PérezRincón, Vargas-Morales y Crespo-Marín, 2018).

Las luchas sociales" se conectan con la llamada "justicia ambiental". Este concepto surge como consecuencia de los discursos sobre el ambiente en Estados Unidos ${ }^{8}$, por parte de los movimientos sociales ${ }^{9}$ con el fin de relacionarlos con temas de justicia social, equidad social, económica y racial, y vulnerabilidad ambiental, toda vez que el modelo de desarrollo no necesariamente coincide con los fines y la agenda de los movimientos ambientales (Arriaga Legarda y Pardo Buendía, 20I I; Shrader-Frechette, 2002) ${ }^{10}$. El concepto de justicia ambiental, asimismo, se ajusta a sociedades con altas concentraciones de minorías raciales o familias de bajos ingresos económicos que están expuestas a los riesgos ambientales. La mayoría de dichos movimientos sociales, busca asegurar que todas las comunidades tengan igual protección ante los riesgos ambientales, así como una sostenible calidad de vida para y de sus miembros (Arriaga Legarda y Pardo Buendía, 20I I).

Existe una evidente frustración de algunos sectores sociales ante los mecanismos legales y las políticas públicas que no han servido para la redirección en el tratamiento de cuestiones ambientales en el país. La democracia se encuentra en crisis. Ya no es percibida como un sistema político en el que todos tienen participación y se propende por el bien común. Por el contrario, es vista como una herramienta de los poderosos para la protección de sus intereses individuales. En este escenario, el concepto de "gobernanza" surge como una propuesta que busca la solución de estos problemas colectivos (Mayntz, 2002). Puntualmente se habla de una "gobernanza ambiental" " que ayude en procesos de toma de decisiones y ejercicio de poder sobre bienes públicos, en los cuales interactúan instituciones gubernamentales, empresas privadas y sociedad civil (Molina, 2014 $)^{12}$. La gobernanza, de igual modo, implica armonizar políticas, instituciones, procedimientos, herramientas e información en torno a la participación de distintos actores públicos y privados, de manera formal o informal, a fin de manejar los conflictos ambientales, instaurar puntos de disenso, tomar decisiones y establecer responsabilidades (Haque, 2017).

La gobernanza quiere revitalizar la democracia haciéndola más participativa, aumentando el poder de decisión de los distintos actores en los ámbitos locales y fortaleciendo la descentralización (Alfie Cohen, 2013). Para ello se deben involucrar esfuerzos del gobierno y los poderes públicos con el fin de realizar políticas, legislar y llevar a cabo juicios justos, en aras del respeto por el ambiente. También la sociedad civil y los medios de comunicación tienen un papel relevante en la vigilancia y control de los entes públicos (Haque, 2017) $)^{13}$.
Teniendo en cuenta el carácter polisémico de la noción de gobernanza ambiental, que puede variar dependiendo del enfoque asumido (nuevo institucionalismo, ecología política, enfoques socio culturales y socio políticos) es necesario establecer sus acepciones más importantes: i) Gobernanza colaborativa: es un paradigma nuevo caracterizado porque el Estado, si bien es un actor en la gestión de lo público, no es el único ni el más importante. Este modelo implica no solo la convocatoria a los diferentes actores sociales con el propósito de decidir e implementar políticas públicas, sino que también modelos de gestión de actores no estatales como organizaciones comunitarias para establecer proyectos de gobernanza. Este tipo de gobernanza se destaca por ser una opción para manejar conflictos socioambientales en los que se pueden requerir opiniones y acciones de los distintos miembros de la sociedad (Trujillo, 2018); ii) Auto gobernanza sostenible: es la capacidad de un sistema organizacional, bien sea de una empresa, corporación, el Estado o una comunidad en particular, de desarrollar sus actividades o tareas sin afectar su ambiente, manteniendo un balance "en las variables esenciales de interacción con su entorno, de forma sustentable y sostenible" (Espinosa, 2018, p. 223).

Se debe aclarar que esta capacidad de autogestión no implica desarrollar competencias de autogobierno. Bajo la tutela de la autogobernanza la acción colectiva es determinante en la regulación del acceso y uso de los recursos naturales; iii) Gobernanza ambiental desde la ecología política: a partir de los trabajos de Castro, Hogenboon y Baud (20I5), es posible identificar una noción de gobernanza ambiental que explica las diferentes dinámicas de América Latina, presentando "las prácticas formales e informales de gestión relacionadas con los recursos naturales renovables y no renovables" (p. 16), como las tensiones y conflictos en torno al reconocimiento de los derechos de la naturaleza, los cambios sociales e institucionales, la influencia de estos en la definición de los patrones de uso de la naturaleza e incluso, el desarrollo de programas de educación popular como mecanismo de protección ambiental y resistencia pacífica a las prácticas extractivas (Ramírez, Hernández y Leguizamón, 2020).

Bajo esta perspectiva, irradiada por un amplio enfoque crítico, la gobernanza ambiental es entendida como "el proceso de formulación y refutación de imágenes, diseños y ejecución de los procedimientos y prácticas que configuran el acceso, control y uso de los recursos naturales entre actores diferentes" (Castro, Hogenboon y Baud, 2015, p. 18); iv) Gobernanza ambiental como forma de actuación informal de la Administración: esta perspectiva desarrollada por Castro Buitrago (2017) trata sobre la vinculación del concepto de gobernanza con la gestión ambiental de forma que se permita el reconocimiento de un nuevo tipo de actuación administrativa capaz de comprender e 
introducir al derecho administrativo ambiental los procesos de participación ciudadana promovidos institucionalmente bajo mecanismos de concertación informal, toda vez que no están regulados por el derecho administrativo tradicional ${ }^{14}$; v) La judicialización de la gobernanza ambiental:es una nueva perspectiva desde la que se puede abordar la categoría que permite explicar la tendencia hacia la resolución judicial a nivel interno y supranacional de las conflictividades socioambientales, exigiendo de los operadores judiciales, enfoques dialógicos para la solución de las tensiones y controversias socioambientales ${ }^{15}$.

De esta manera, la gobernanza ambiental, en cualquiera de sus modalidades, pone de manifiesto la insuficiencia de los mecanismos administrativos de carácter unilateral para manejar y superar las crisis ambientales y para ello propone un nuevo tipo de actuación administrativa capaz de comprender el fenómeno y superar el anacronismo de la administración bajo nuevas formas que no se encuentran adscritas a las diseñadas por el ordenamiento (Castro Buitrago, 2017).

La gobernanza nace de un nuevo enfoque de la administración. Busca hacerla más eficaz y cercana al ciudadano. Esto necesariamente envuelve la implementación de políticas de diálogo ante las injusticias ambientales - más no de represión y criminalización de la protesta-. Llevar a cabo esta forma de gobierno significa aterrizar la construcción de la política ambiental, para contar con una participación activa y de peso en la toma de decisiones de la administración, evitando, en ese sentido, ser una simple herramienta que sirva para legitimación de políticas prestablecidas (Cerrillo Martínez, 2005). La toma de decisiones en el ámbito de la gobernanza ya no tiene un control jerárquico, los participantes tanto públicos como privados llegan a consensos. En Colombia el concepto de gobernanza, en un primer momento, se ha confundido con el de gobernabilidad. Sin embargo, luego fue incorporado con más claridad en el Plan Nacional de Desarrollo 1994-1998 "el salto social", en donde se establecía la participación ciudadana para el logro de un "Buen Gobierno" tratando de incorporar en la agenda pública este concepto (Castro-Buitrago, 20II), no obstante no existe una política de diálogo concreta con la ciudadanía.

Establecida la gobernanza como método de gestión del ambiente, la discusión sobre su aplicabilidad no es pacífica. La gobernanza implica un trabajo mancomunado de los distintos sectores de la sociedad, movimientos ambientales, grupos de empresarios, sindicatos, organizaciones científicas y el Estado, en aras de llegar a una concertación (Alfie Cohen, 20I3). Así, la base de la gobernanza se encuentra en los ejercicios de diálogo que presuponen un reto para los actores, ya que exige la construcción de confianza y un 206 y, particularmente, los movimientos sociales que plantean otras perspectivas, incluso contrarias sobre el modelo de desarrollo. Por ejemplo, en Latinoamérica se ha planteado un pensamiento crítico al modelo político y de desarrollo.

En particular los pueblos indígenas andinos han promovido la idea del "buen vivir" en contraposición al "mal vivir" en el que se establece el bienestar en la tenencia material y crecimiento económico (Molina y Rojas, 2019). Esta idea es una manifestación propia sobre el pensamiento ambiental, con el fin de alcanzar un desarrollo armónico con la naturaleza, lo que implica una reconstrucción del modelo de gestión estatal. Las nuevas tendencias sobre el manejo y concepción del ambiente incluso se han reflejado en algunas conferencias que se realizaron en América Latina como la Cumbre de Rio de 2002 o la reunión del COP de 2014, celebrada en Perú (Valverde Garnica, 2016). El Papa Francisco (2014) de igual manera, ha planteado la necesidad del decrecimiento en ciertas partes del mundo, para proporcionar recursos con el fin de que otros puedan desarrollarse sanamente.

La dinámica de los movimientos sociales se ha planteado en esa línea, es decir en una reflexión sobre los beneficios reales de la extracción de recursos y las vías alternativas de desarrollo por fuera del paradigma moderno occidental de bienestar basado en la explotación indiscriminada de los recursos naturales y ambientales, aludiendo a que dicho modelo de crecimiento económico es inviable, además de injusto por lo que, en conclusión, se debe cambiar por otro modelo, más sostenible que obligue a transformaciones de fondo en la formas de producción tradicionales (Asara et al. 2015). De esta manera, dichas concepciones contrahegemónicas de la ciudadanía y movimientos sociales hacen un contrapeso significativo a las lógicas estatales que se encuentran afincadas en el extractivismo como modelo de crecimiento $^{16}$. La gobernanza, entonces, tiene como desafío la búsqueda de mecanismos para poner en diálogo a cada uno de los actores con el fin de establecer políticas dialogadas y concertadas.

Teniendo claro esto, es necesario precisar que los problemas del ambiente no se agotan en la regulación nacional, por lo que se debe examinar el ámbito supranacional (Valverde Garnica 2016). Los procesos de gobernanza no solamente han de involucrar a los actores de los casos especíicos, sino que deben tener en cuenta las políticas públicas macro nacionales e internacionales que se implementen para la gestión de los recursos naturales. Los modelos de gobernanza tienen que atender a cada contexto, a través de la participación efectiva de la ciudadanía y, al mismo tiempo, debe tener en cuenta el panorama general de incidencia nacional e internacional. 
Esta necesidad de glocalidad hace que la gobernanza ambiental se enfrente a diferentes desafíos a saber: i) la implementación de una política multilateral con acuerdos a nivel nacional, regional y, por qué no, global; ii) el desarrollo progresivo e incidente dentro de las políticas nacionales; iii) encontrar los recursos necesarios para resolver los conflictos de intereses; iv) asegurar presupuesto a largo plazo; v) articular instituciones y organizaciones sociales; vi) priorizar el ambiente ante aspectos, que se pueden considerar aún más importantes para el desarrollo nacional, como la agricultura o la extracción de hidrocarburos; vii) concienciar a los diferentes agentes y sectores públicos de la necesidad del cuidado del ambiente (Haque, 2017) $y$; viii) establecer un diálogo técnico e informado entre las partes, para promover acciones acertadas, en un marco consensuado.Aunque esto último constituye un reto doble ya que, por un lado, la ciudadanía no todas las veces puede estar informada sobre los alcances técnicos de la política pública, $y$, por otro, puede ejercerse manipulación por parte del Estado, para favorecer a sectores específicos y en detrimento de las comunidades directamente afectadas.

Hasta ahora los resultados de los movimientos sociales en la gobernanza pueden ser importantes, pero no determinan mayores cambios en inclusión social económica, solamente algunos de responsabilidad social empresarial. Los actores económicos tienen más poder que los movimientos sociales, lo que determina su capacidad de dominar las discusiones y determinar sus resultados (Bebbington, Abramovay y Chiriboga, 2008). No obstante, la gobernanza como participación, en los términos de Schlosberg (2004) es uno de los elementos relevantes de la justicia ambiental. Las políticas públicas no le pueden dar la espalda al pueblo, ser ilegítimas y tampoco pueden desconocer el clamor de la tierra y de las comunidades que sufren los efectos de la depredación del ambiente.

La noción de gobernanza ambiental en Colombia sustenta la acción ambiental como un acto jurídico de naturaleza pública, enmarcada en el principio de legalidad y legitimidad democrática. Los presupuestos mínimos, para su desarrollo, han sido dados por el cumplimiento de una competencia de las autoridades para emprender negociaciones sobre materias lícitas con las comunidades afectadas y demás sectores sociales directa o indirectamente, por la decisión administrativa. Además, en algunas ocasiones, tanto la Corte Constitucional como el Consejo de Estado han asumido el control de la actividad administrativa cuando se ha omitido la consulta previa en medidas legislativas, afectando con ello los derechos fundamentales de los pueblos, especialmente los grupos étnicos y raizales. Incluso en las decisiones previas, se han establecido parámetros jurídicos en los que se examinan aspectos que conciernen al proceso de consulta (Castro Buitrago, 2017).
Lo que se busca con la Gobernanza ambiental, a través de los mecanismos de diálogo y conformación de políticas concertadas, es retomar la justicia en torno al ambiente, especialmente en los sectores más vulnerables y lograr la "paz ambiental territorial", entendida como la reconstrucción de un orden social antes integrado por conflictos ambientales (Molina y Rojas 2019).

\section{Aproximación a las conflictividades ambientales en el bosque alto andino de Boyacá}

En la actualidad el Ministerio de Ambiente y Desarrollo Sostenible ha emitido 36 actos administrativos para delimitar el número páramos en el territorio colombiano (Minambiente, 2009). De acuerdo con Rivera Ospina (201 I), los ecosistemas de páramo en Colombia presentan una extensión aproximada de 1.925.410 hectáreas, de las cuales 346.644 están ubicadas en áreas de parques nacionales naturales, y un porcentaje significativo (19\%) de las hectáreas de parques naturales se encuentran en la jurisdicción del departamento de Boyacá (Ver Figura I).

Como se puede advertir, el departamento de Boyacá concentra un alto número de complejos ecosistémicos de páramo, que incluyen áreas de subpáramo o páramo bajo y bosque alto andino. No obstante, estas áreas, también cuentan con un alto número de polígonos mineros y de hidrocarburos que, sumados a los procesos antrópicos impulsados por la actividad agropecuaria, ponen en riesgo la sustentabilidad e integralidad de los ecosistemas. Esta es una de las variables que explica por qué un buen porcentaje de ecosistemas de páramo, subpáramo y bosque alto andino se encuentran antropizados. De hecho, se estima que cerca de la mitad de los 85 ecosistemas clasificados en Colombia están amenazados, presentándose mayor vulnerabilidad y afectación en los páramos, en donde se presentaba una tasa anual de pérdida de ecosistema cercana al 17\% entre 1985 у 2005 (WWF-Colombia, 2017).

Sin duda, un esfuerzo crucial para controlar el acelerado proceso de perdida de los ecosistemas de páramo, está materializado en las 36 delimitaciones realizadas en los últimos años por el Ministerio de Ambiente; sin embargo, este esfuerzo no será suficiente si no se empieza a profundizar en la regulación y protección de los ecosistemas que tienen una función protectora sobre el páramo, así como de regulación del recurso hídrico. Este es el caso de los ecosistemas del bosque alto andino. En otras palabras, el páramo debe entenderse como un sistema que funciona de manera integrada e interdependiente con los demás ecosistemas, de tal suerte que, si no se articula de mejor forma la protección del páramo con los demás ecosistemas, la efectividad de los mecanismos de conservación de los 


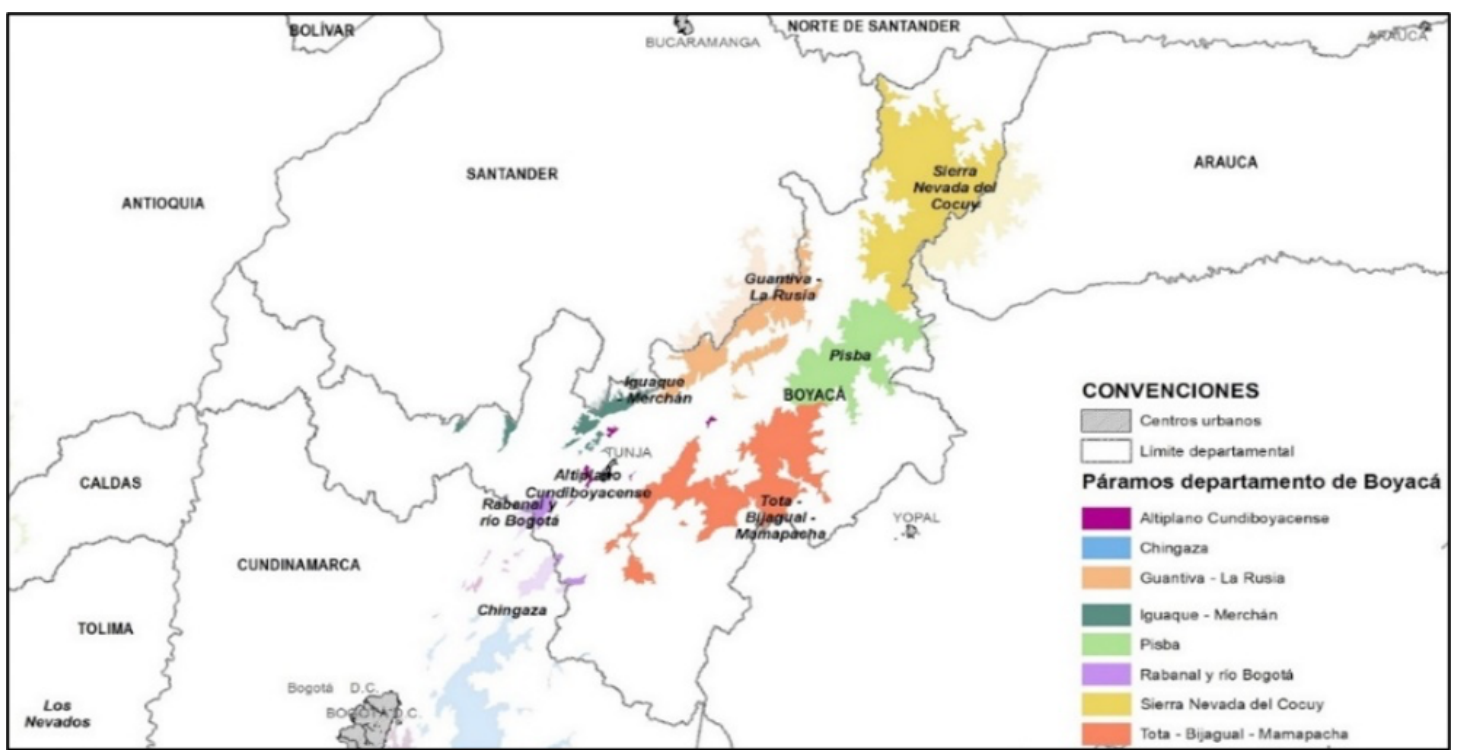

Figura I. Ubicación de páramos en Boyacá - "Socialización Páramos de Boyacá"

Fuente: Ministerio de Ambiente y Desarrollo Sostenible (2017)

sistemas paramunos no será la esperada. En este sentido, la importancia del bosque alto andino está dada porque "constituye una zona de ecotonía entre la vegetación cerrada de los bosques o selva y la vegetación abierta de matorrales y pajonales de la parte alta" (Rivera Ospina, 201 I, p. 23).

\section{I Conflictividades ambientales asociadas a hidrocarburos}

De acuerdo con la Agencia Nacional de Hidrocarburos $(\underline{A N H}, 2018)$, en la jurisdicción del departamento de Boyacá se han asignado 12 contratos de exploración y producción de hidrocarburos vigentes, los cuales están ubicados en los municipios de Paya, Paz del Río, Pesca, Pisba, Tasco y Tota.

Para identificar cuántos y en qué proporción de área autorizada en zona de bosque alto andino se encuentran estos contratos, la Agencia Nacional de Hidrocarburos sobrepuso los ecosistemas asociados al bosque andino descritos en el mapa de ecosistemas continentales, costeros y marinos de Colombia, versión 2.I, escala I:I00.000 publicado en el año 20I7, utilizando información correspondiente a los atributos «ecosistemas terrestres» y «ecos- general» que se describe en el mapa de ecosistemas, incluyendo los descriptores que podrían estar más asociados al bosque alto andino, cómo bosque andino seco, arbustal andino húmedo, bosques galería basal húmedo, bosques de galería basal seco, bosque subandino húmedo, bosque subandino seco, arbustal basal húmedo, arbustal subandino andino húmedo, herbazal basal húmedo y herbazal sub andino húmedo. De esta manera, la Agencia Nacional de Hidrocarburos concluyó que:

los porcentajes de ecosistemas natural dentro de los contratos de hidrocarburos son inferiores al 5\%; el total del área que se intersecta corresponde a 17322 hectáreas de un total de 60000 hectáreas de estos tipos de ecosistemas que se encuentran en los municipios descritos (ANH, 2018, p.2).

Esto quiere decir que, el área asignada para la exploración de hidrocarburos en los Municipios de Paya, Paz del Río, Pesca, Pisba, Tasco y Tota en el departamento de Boyacá, comprende 1728202, 16 hectáreas, de las cuales 17321,86 están sobrepuestas en bosque andino (Ramírez y Leguizamón, 2020a) (Ver Figura 2). Llama la atención el caso del municipio de Paya, en cuya jurisdicción se concentran 6 contratos para la exploración hidrocarburos, que sumados contemplan 9394,5 ha., de bosque andino, equivalentes al $9,87 \%$ del área total de bloques petroleros asignados en Paya.

Igualmente es significativa el área de bosque denso alto de tierra firme, dentro de la jurisdicción del municipio de Pisba afectado inscrito en el contrato exploración de hidrocarburos denominado «mundo nuevo» firmado con la operadora Hocol S.A, al contemplar dentro de su bloque cerca del $3,305 \%$ de área de bosque andino, que equivale a cerca de 6393,39 hectáreas (Ver Figura 3). 
En igual sentido, los bloques petroleros para la exploración de hidrocarburos contemplan áreas de bosque andino de los municipios de Paz del Río con 99.I ha., Pesca con I 3 I 7, 12 ha., Tasco con 48,39 ha., y el municipio de Tota con 69.36 hectáreas de bosque andino (Ver Figura 4).

De esta manera, se puede observar que los bloques petroleros en el departamento de Boyacá están integrados por un $9 \%$ de área catalogada como bosque andino.

\subsection{Conflictividades asociadas a minería}

Boyacá es el segundo departamento con más títulos mineros en Colombia (ANM, 2018), al presentar I.574 títulos mineros vigentes "que representan un área de
318.637 hectáreas, un 14\% del departamento" (ANM, 20I5, p. I). En once de los municipios estudiados (Samacá, Tasco, Tota, Paipa, Socha, Duitama, Pesca, Iza, Tunja, Sogamoso y Nobsa), se identificaron 455 títulos Mineros -el 28\% de los títulos asignados dentro del Departamento-, de los cuales el $32 \%$ están ubicados en la jurisdicción de Sogamoso, el I $3 \%$ en la jurisdicción de Tasco, el I $3 \%$ en Paipa, el II\% el municipio de Tunja, el $7 \%$ en el municipio de Socha, el $6 \%$ en Pesca, otro $6 \%$ en Samacá, $4 \%$ en Duitama, $4 \%$ en el municipio de Iza, $3 \%$ en el municipio de Nobsa y un $1 \%$ en el municipio de Tota (Ver Figura 5).

En el caso del complejo del páramo de Pisba, la actividad minera y de exploración de hidrocarburos convergen en la

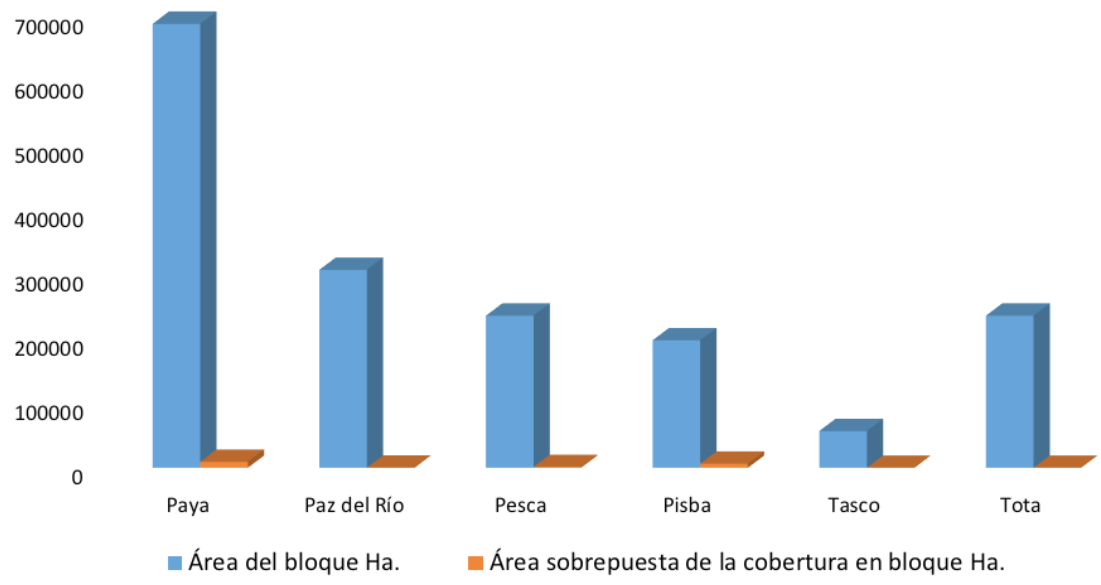

Figura 2. Área de bloques petroleros sobrepuesta sobre cobertura de bosques andinos en ha. Fuente: Elaboración propia basados en información de la Agencia Nacional de Hidrocarburos radicado $201864 \mid 027559$ | del 13 de septiembre de 2018.

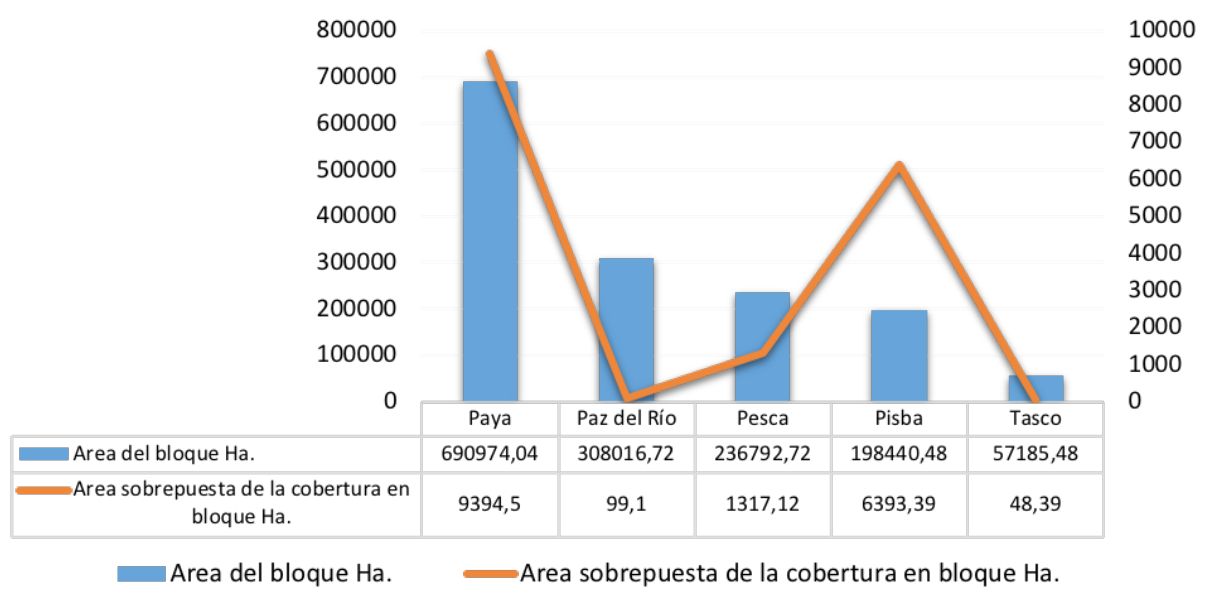

Figura 3. Área de bloques petroleros sobrepuesta sobre cobertura de bosques andinos en ha. Fuente: Elaboración propia basados en información de la Agencia Nacional de Hidrocarburos radicado 2018641027559| del I3 de septiembre de 2018. 


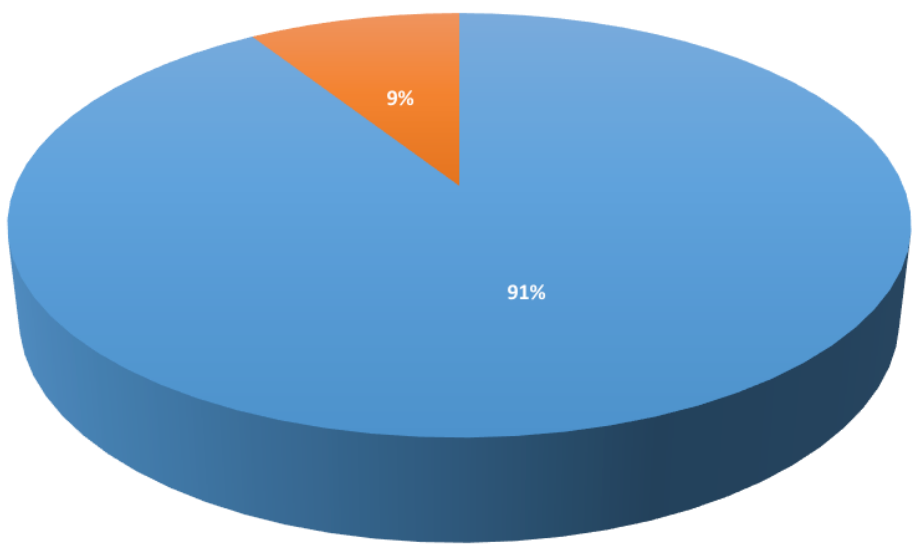

- Area del bloque Ha. Area sobrepuesta de la cobertura en Bloque $\mathrm{Ha}$

Figura 4. Área de bloques de hidrocarburos y \% de intervención en bosque andino en el Departamento de Boyacá. Fuente: Elaboración propia basados en información de la Agencia Nacional de Hidrocarburos radicado 20186410275591 del 13 de septiembre de 2018.



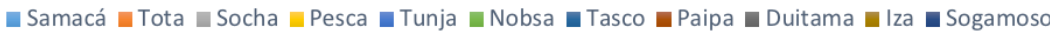

Figura 5. Distribución porcentual de titulos mineros por municipio.

Fuente: Elaboración propia basados en información suministrada por la Agencia Nacional de Minería mediante respuesta de derecho de petición $N^{\circ} 2018903042335$ I del 19 de septiembre de 2018, reporte catastro y registro minero, corte $31 / 08 / 2018^{17}$.

jurisdicción del municipio de Tasco y Socha, concentrándose allí buena parte de las conflictividades socioambientales asociadas con el ecosistema del páramo de Pisba y sus ecosistemas adyacentes. Esta misma convergencia entre minería y solicitudes de exploración de hidrocarburos, se presenta en el complejo de páramos ecosistemas adyacentes de Tota - Bijagual - Mamapacha, específicamente en la jurisdicción del municipio de Tota y Pesca. El caso de 210 las conflictividades socioambientales están vinculadas a la explotación y sobreexplotación de carbón.

\section{Casos de gobernanza ambiental: experiencias en los Páramos de Pisba y Tota - Bijagual - Mamapacha}

De acuerdo con la última cartografía de recursos biológicos del Instituto Alexander von Humboldt (20I2), la superficie 
del complejo de páramo de Pisba comprende cerca de 106.243 hectáreas (Ver Figura 6).

Este territorio presenta constantes tensiones sociales y económicas, que han impedido la delimitación y clasificación de sus recursos ambientales. Una de las razones, de las tensiones mencionadas, está vinculada al alto número de habitantes dentro del complejo del páramo, estimado en cerca de 12.000 personas, muchas de ellas dedicadas a la actividad agropecuaria y minera. En este páramo se registran al menos 18 títulos mineros otorgados por la ANM y sólo en el municipio de Tasco, se han promovido cerca de 14 licencias ambientales para el desarrollo de actividades de minería desde el año 200I (Vega, 20I7). En contraste con esta tendencia, también se han identificado diversos medios constitucionales para proteger derechos colectivos afectados con la explotación minera, como el caso de las acciones populares radicadas entre el año 2008 y 2013 , cuyo número asciende a cinco (Vega, 2017).

La radicalización de posiciones entre quienes promueven la actividad extractiva y quienes buscan la protección del ambiente, ha trasladado los ejercicios de gobernanza ambiental a las autoridades judiciales. Acciones que han impulsado a la tendencia de judicialización de la gobernanza ambiental, lo que obliga a que la decisión en torno a la forma de administración de los recursos naturales sea asumida directamente por el poder judicial. Este tipo de gobernanza se resuelve bajo un paradigma dialógico por parte del sistema judicial. No obstante, el principal riesgo de este mecanismo, son las ilimitadas atribuciones que entrega la gobernanza ambiental a un juzgador, que por lo general, no conoce la realidad social y las complejidades del territorio objeto de la decisión.

Un ejemplo de este tipo de gobernanza fue la acción popular (Radicado 2014-223) promovida por la Defensoría del Pueblo en contra de la Sociedad Carbones Andinos y otros. Allí, el Consejo de Estado declaró a estos últimos, como responsables por la afectación al derecho colectivo a un ambiente sano, el equilibrio ecológico y al manejo y aprovechamiento racional de los recursos naturales. Como consecuencia, el alto tribunal ordenó a Carbones Andinos abstenerse de realizar actividades de explotación de carbón en el polígono al que se refiere la concesión número fgd-|4|, hasta que, dicho proyecto contara con una licencia ambiental. Dicha licencia fue otorgada gracias al proyecto aprobado mediante Resolución GTRN- 357 del 28 de octubre del 2010 . Asimismo, acudiendo al principio de precaución en materia ambiental, el máximo Tribunal de lo Contencioso Administrativo exhortó a la ANM a abstenerse de otorgar nuevos títulos mineros dentro de cualquier área incluida en la delimitación del páramo de Pisba, hasta ahora realizada por el Instituto von Humboldt, mientras se delimita el páramo por parte del Ministerio de Ambiente.

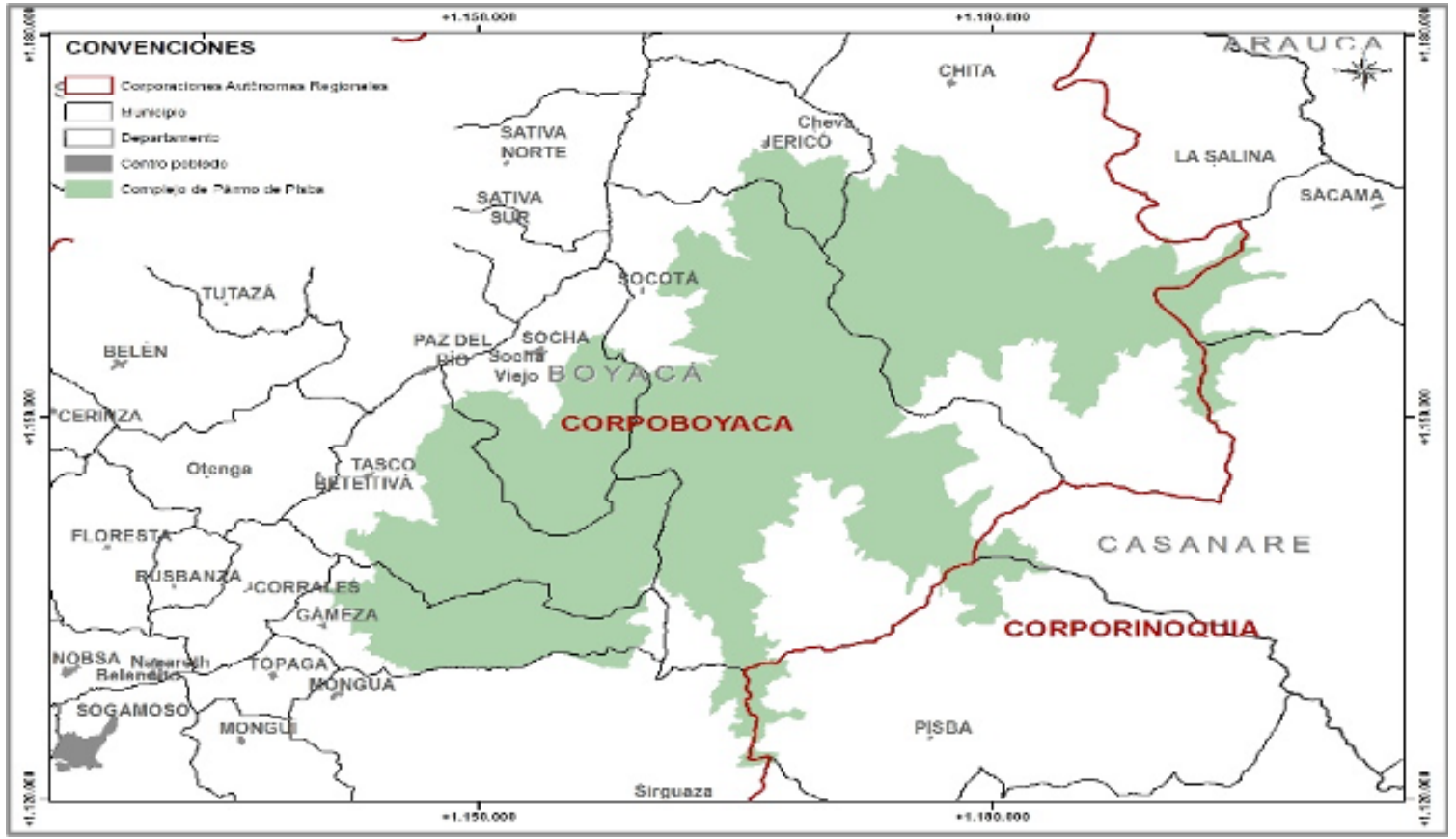

Figura 6. Ubicación del páramo de Pisba

Fuente: Ministerio de Ambiente y Desarrollo Sostenible (2017). 
Otro ejemplo de la judicialización de la gobernanza ambiental es la acción de tutela interpuesta por la señora Cenaida Ramos Estupiñán como mecanismo transitorio, contra Minas Paz del Río / Votorantim, resuelta por la Corte Constitucional en Sentencia T-34I de 2016, donde protegió el derecho fundamental a la vida digna de la accionante y estableció entre otras medidas, la orden a la empresa Minas Paz del Rio/Votorantim, para que proceda a realizar las adecuaciones técnicas y a dar cumplimiento a los requerimientos de las autoridades ambientales $y$ mineras, a fin de mitigar los daños ambientales generados por la actividad minera de la empresa accionada. Este caso responde a un ejercicio de defensa del derecho al ambiente sano impulsado por la comunidad con el acompañamiento de organizaciones gubernamentales -como el caso de la Defensoría del Pueblo- y no gubernamentales. De esta manera, se hizo uso de las herramientas del derecho con el propósito de hacer valer la intervención de la ciudadanía, en los procesos de toma de decisiones. En este sentido, podemos establecer que existe una judicialización de la gobernanza ambiental en la medida en que son los actores sociales los que acuden a los estamentos judiciales ante el aparente rompimiento de los canales de diálogo social necesarios para el desarrollo de procesos exitosos de gobernanza ambiental.

Otro modelo se desarrolló en las zonas de Tota y Pesca, en las que se optó por una gobernanza colaborativa. Mediante Resolución 2000 del 16 de octubre de 2009, el entonces Ministerio de Ambiente, Vivienda y Desarrollo Territorial, otorgó licencia ambiental a la empresa Hocol S. A., para el proyecto «Área de Interés Exploratorio Muisca», localizado en jurisdicción de los municipios de Pesca y Tota, en el departamento de Boyacá. En este se incluyeron dos áreas de interés denominadas Suamox y Bachué. Posteriormente, mediante Resolución 553 del 16 de marzo de 2010, el Ministerio en mención, autorizó la cesión de la licencia ambiental otorgada por Resolución 2000 de 2009, a favor de la empresa Maurel \& Prom Colombia B.V.

Perfeccionada la cesión, mediante auto $\mathrm{N}^{\circ} 78$ del 17 de enero de 2012, la Autoridad Nacional de Licencias Ambientales (ANLA), dio inicio al trámite administrativo, de modificación de la licencia ambiental otorgada para así, autorizar la ampliación del área del proyecto, la construcción y operación de nuevas obras, y adicionar y/o modificar permisos para el uso de recursos naturales (Ver Figura 7).

Conocido el inicio del trámite de licenciamiento ambiental, las comunidades, líderes sociales, campesinos y colectivos ambientales iniciaron un proceso de visibilización de las eventuales consecuencias, que un proyecto de explotación de hidrocarburos traería para los ecosistemas aledaños a 212 tercero interviniente, contemplada en el artículo 69 de la Ley 99 de 1993, se pudieran introducir al proceso, los estudios y conceptos elaborados por diferentes autoridades, la comunidad académica y la sociedad civil en general.

Asimismo, la comunidad, colectivos ambientales y organismos de control, promovieron y participaron en la audiencia pública ambiental, establecida en el artículo 72 de la Ley 99 de 1993. A partir de este mecanismo de participación en asuntos de materia ambiental, se presentaron dos solicitudes para la celebración de audiencia ambiental en el marco del proyecto. La audiencia tuvo lugar el 29 de septiembre de 2016 y el 6 de noviembre de 2016 .

Como consecuencia de este ejercicio de participación ciudadana, la Autoridad Nacional de Licencias Ambientales, mediante Resolución $N^{\circ} 929$ del 8 de agosto del año 2017 decidió negar la modificación de la licencia ambiental para el proyecto mencionado. Entre otras consideraciones, por la cercanía del Páramo de Tota - Bijagual - Mamapacha -a menos de $30 \mathrm{~m}$ - con los límites del área propuesta -área reducida- para el proyecto, sin el establecimiento de una zona de amortiguación que atenuara y previniera el impacto sobre el ecosistema. Además, en aplicación del principio de prevención, en el entendido de que existen limitaciones ambientales y técnicas para el manejo apropiado de los impactos que generaría el proyecto, en consideración a la sensibilidad e importancia del ecosistema -flora, fauna y riqueza hídrica, entre otros- y considerando que no existía certeza de que se podría realizar una adecuada protección, prevención o mitigación de impactos.

Este caso de gobernanza colaborativa ofrece varias reflexiones: la primera de ellas está relacionada con la experiencia exitosa del proceso donde, a partir de la gestión de la comunidad, se logró la articulación de la mayoría de las autoridades del orden local, departamental y nacional, para la protección del páramo y su bosque andino. Dicha articulación se logró gracias a la capacidad de organización de los colectivos ambientales que asesoraron a las comunidades afectadas con el proyecto extractivo. En este caso también, se puede verificar que el proceso de participación ciudadana ya se encuentra establecido en las normas y es la ciudadanía la que, a partir del aprovechamiento de esas herramientas, puede hacer valer su posición con éxito. En ese sentido, los movimientos sociales se han venido capacitando e informando de las distintas facultades que las normas les han dado. Ahora es más frecuente el uso de las herramientas administrativas y judiciales para hacer valer el derecho a la participación y con ello también expresar sus modelos de desarrollo de corte contrahegemónico.

Es en estos procesos de gobernanza, cuando la comunidad decide para sus recursos naturales un destino diferente 


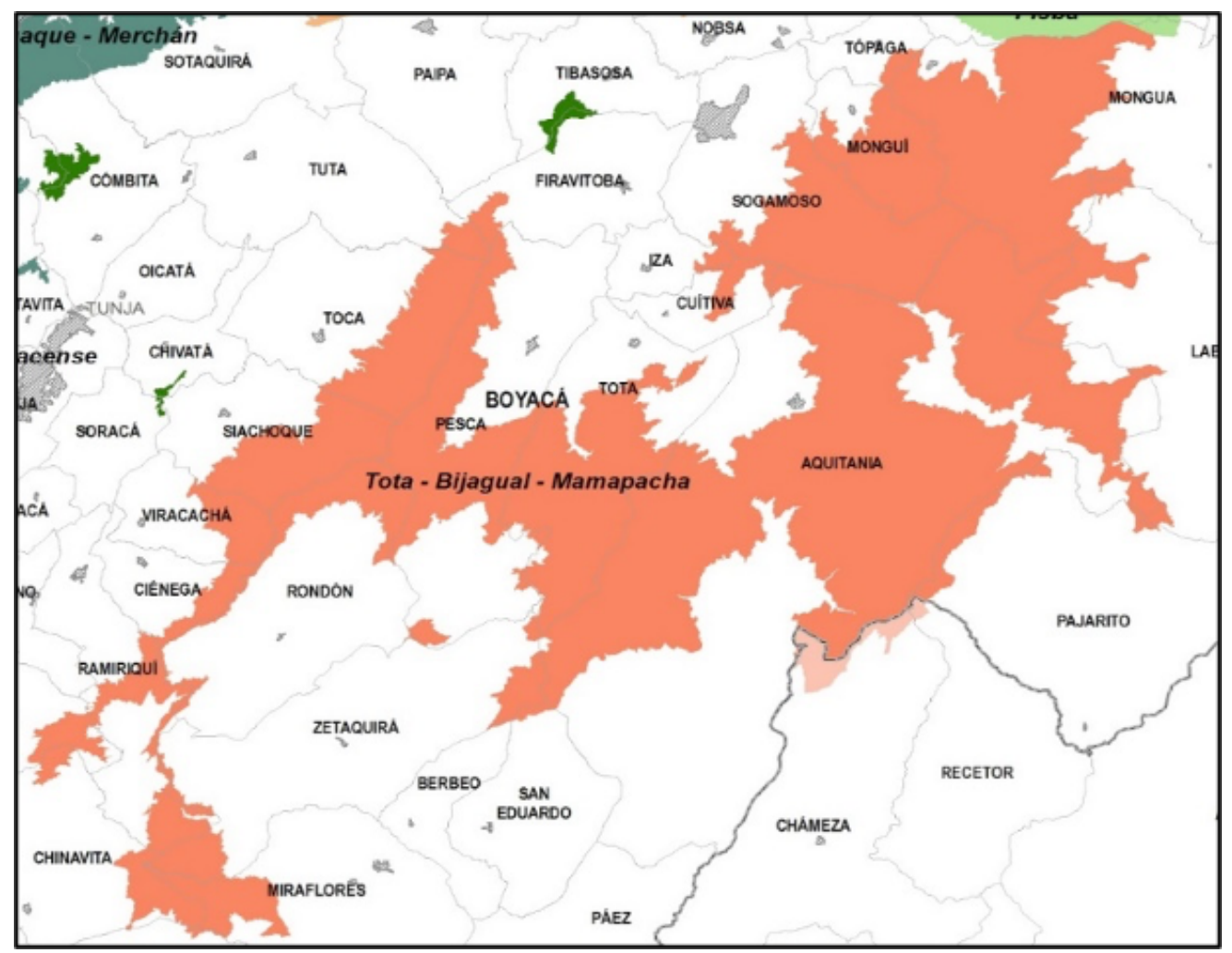

Figura 7. Ubicación del páramo de Tota - Bijagual -MamapachaFuente: Ministerio de Ambiente y Desarrollo Sostenible (2017)

al pretendido por las trasnacionales interesadas en la explotación de commodities, donde cobra importancia la noción de "glocalismos", para expresar la interacción entre lo global y lo local, permitiendo comprender cómo la globalización se localiza (Palacios, Prada y Laguado, 2017) y "cómo las culturas locales pueden adaptarse o resistir de manera crítica a los fenómenos globales" (Preyer, 2016, p. 66). En este caso fue posible advertir, cómo las comunidades, prevenidas de los efectos adversos del extractivismo, se rehúsan a aceptar la implementación de proyectos de explotación de recursos naturales en sus territorios, dando prelación a valores asociados a la conservación ambiental, por encima de los conceptos globales de crecimiento y desarrollo económico.

A partir de estos ejemplos de gobernanza, surge un debate cultural mucho más profundo, que pone en el centro de la discusión la consideración ética de la naturaleza, a partir del cuestionamiento a los valores inmersos en los procesos globalizantes. De esta manera se podría explicar la aparición de concepciones éticas que justifican el trato a la naturaleza como sujeto de derechos, como se dio recientemente cuando el Tribunal Administrativo de Boyacá (2018) ${ }^{18}$ reconoció al paramo de Pisba como sujeto de derechos y que en principio colisionan -o al menos cuestionan- la concepción ética inmersa en la idea global de desarrollo económico extractivista.

\section{Conclusiones}

El sistema internacional económico predominante ha concentrado la economía en la extracción de commodities provocando situaciones de "injusticia ambiental" 19 en los territorios, si se tiene en cuenta que, las personas más débiles y vulnerables económicamente son las que soportan desproporcionadamente los efectos de la explotación ambiental. Estas situaciones de injusticia generan inconformidades ciudadanas que se reflejan en procesos de protesta social y propuestas de modelos alternativos de desarrollo. En este sentido, los fenómenos sociales tienen elementos "glocales" es decir una mezcla de fenómenos locales y globales.

La idea de gobernanza ambiental, como un conjunto de reglas prácticas políticas e instituciones en torno al manejo de ambiente, se convierte en una alternativa para el alivio 
de las tensiones de los distintos actores, en el marco de procesos de diálogo y de decisión política, en los que haya una participación ciudadana activa, y se promueva la concertación social. Mediante la gobernanza ambiental se quiere dar un nuevo aire a los procesos democráticos, e impulsar políticas fundamentadas en la intervención de todos los actores (campesinos, indígenas, trabajadores, dueños de medios de extracción, gobierno, etc.). Los desafíos de los procesos de gobernanza consisten en i) permitir un diálogo en igualdad de condiciones no solo en términos de mediación, sino en documentación e información asertiva entre las partes, que permita la equidad en las relaciones de poderes, y ii) procurar que los mecanismos de diálogo no sean una simple herramienta formal para dotar de falsa legitimidad a las medidas que se adopten.

En Boyacá, se han encontrado conflictos ambientales derivados de la explotación minera y de hidrocarburos que afectan a los páramos de Pisba y Tota - Bijagual-Mamapacha, junto con sus áreas de amortiguación. Especialmente la minería tiene gran importancia como actividad de impacto, quedando establecido que el departamento tiene el segundo lugar en títulos mineros. Es allí donde la gobernanza cobra relevancia como forma de gestión del conflicto.

Particularmente en el texto se analizaron dos casos en el Departamento de Boyacá. El primero tiene que ver con la judicialización de la gobernanza en el caso del páramo de Pisba. Este territorio de 12.000 personas con actividad minera y agropecuaria concentra una problemática importante, en relación con el ambiente. Los distintos procesos de discusión sin resultado y la contradicción entre el extractivismo y la protección del ambiente han tenido como consecuencia diversas acciones judiciales. Han sido los tribunales los que han tenido que solucionar las controversias provocadas por los actores en esta zona e incluso promover los procesos de gobernanza, como sucedió con la sentencia de la Corte Constitucional T-36I de 2017, en donde se declara la suspensión del trámite de delimitación del páramo de Pisba, por considerar que no existió la participación de las comunidades. Asimismo, en el marco del uso de las acciones judiciales cómo método de solución de conflictos, el Tribunal Administrativo de Boyacá profirió sentencia en la que se declara al Páramo de Pisba como sujeto de derechos ${ }^{20}$, complejizando el panorama sobre las medidas que se deben adoptar.

Lo anterior corrobora la categoría propuesta de "judicialización de la gobernanza ambiental" como quiera que los jueces pueden provocar procesos de diálogo entre las partes. Por una parte, el aparato judicial como interviniente frente a asuntos en los que no se ofreció procesos de diálogo o de consulta previa. En esa medida 214 exigen intervención ciudadana. Por otro lado, los procesos judiciales pueden enmarcar procesos de diálogo entre las partes para la toma de decisiones concertadas, por ejemplo, en el marco de las acciones populares, cuando las partes realizan pactos de cumplimiento y en sus audiencias de supervisión del cumplimiento del mismo. En ese sentido, es importante la presencia del activismo judicial dialógico que se ha presentado en varios escenarios judiciales, especialmente constitucionales.

El segundo caso tiene que ver con el análisis de la gobernanza colaborativa en los municipios de Tota y Pesca. La experiencia de gobernanza giró en torno a la ampliación de la licencia para el proyecto "Área de Interés Exploratorio Muisca" otorgado para la explotación de hidrocarburos que provocó una reacción de las comunidades. Allí la intervención ciudadana se logró a partir del uso de la figura de tercero interviniente establecido en el artículo 69 de la Ley 99 de 1993. La intervención ciudadana ayudó a que se tomara la decisión de negar la ampliación de la licencia. Allí la experiencia de gobernanza se hace gracias al aprovechamiento de los espacios ya establecidos normativamente, más que a la búsqueda estatal de una estrategia de diálogo.

Sumado a lo anterior, los casos evidencian que los procesos de gobernanza ambiental constituyen mecanismos de resistencia local frente a una idea globalizante de desarrollo económico, que justifica la explotación exacerbada de los recursos naturales. Este glocalismo expresa la divergencia, respecto al valor intrínseco de la naturaleza, así como de la concepción de desarrollo, expresada en los procesos de participación ciudadana propiciados por las comunidades preocupadas por los efectos negativos que el extractivismo puede generar en sus territorios.

\section{Conflicto de intereses}

Los autores declaran no tener ningún conflicto de intereses.

\section{Notas}

I. El modelo aplicado en Colombia es el de extractivismo convencional cuyo objeto principal "es alcanzar altas tasas de crecimiento económico a través del estímulo de las exportaciones" (Portillo, 2014, p. I5).

2. El neoextractivismo tiene los mismos rasgos del extractivismo, la diferencia está dada en el papel regulador del Estado para corregir las fallas del mercado (Portillo, 20I4).

3. Por razones metodológicas y de pertinencia, del presente artículo se excluye el análisis de las conflictividades socio ambientales del departamento de Boyacá, las variables 
asociadas a la relación de la naturaleza con el conflicto armado colombiano, esto es, "la naturaleza como causa del conflicto armado, la naturaleza como mecanismo de financiación y reproducción del conflicto, la naturaleza como víctima del conflicto y por último, la naturaleza como beneficiaria del conflicto" (Ramírez y Leguizamón, 2020b, p. 267).

4. Aunque también es claro que muchas veces las multinacionales descentralizan la producción a los países pobres con débiles legislaciones laborales para establecer allí sus centros de producción.

5. Esto también con frecuencia se utiliza el término neoextractivismo. Sin embargo, como lo reconoce Lander (20l4) las diferencias de la terminología entre estos conceptos no es trascendental y por el contrario se sigue confiando el modelo de desarrollo a la extracción de recursos naturales.

6. De hecho los estudios como el atlas global de justicia ambiental (EJAtlas) se desprende que, así como en los países desarrollados las desigualdades afectan a los más pobres, a nivel global los países más pobres son los que más sufren de injusticias de este tipo, especialmente en Sudamérica (Temper, Demaria, Scheidel, Del Bene, \& Martinez-Alier, 2018)

7. En la historia de Colombia, las luchas sociales siempre han estado presentes, Sin embargo, los movimientos sociales propiamente dichos se instauraron durante la época del frente nacional (Archila, 200I). En los años setenta el surgimiento de los movimientos ambientales también influenció la creación de instituciones y la creación de algunas ONG's como la Fundación Herencia Verde y Cosmos, que trajeron nuevas perspectivas en torno a lo ambiental, la conservación los problemas sociales y las protestas contra el desarrollo (Ulloa, $\underline{2001)}$.

8. De hecho, iniciativas como el EJAtlas surgen como consecuencia del movimiento de Estados Unidos establecido en los años 80's, fundando en la inequitativa repartición de beneficios ambientales a las personas afroamericanas (Temper et al. 2018).

9. Estos fueron influidos por la industrialización y los movimientos conservacionistas preocupados más por la contaminación que por elementos de justicia social (ShraderFrechette, 2002)

10. Shrader-Frechette (2002) también define la justicia ambiental de manera negativa, es decir que indica la existencia de injusticia ambiental cuando algunos individuos o grupos soporta riesgos ambientales desproporcionados como vertederos de residuos, o no tienen acceso a bienes ambientales como aire limpio, o la oportunidad de participar en la toma de decisiones.

II. Un hito especial respecto al uso del término "gobernanza ambiental” fue la publicación en 200 I del Libro Blanco sobre gobernanza europea, la gobernanza en el consenso europeo sobre la política de desarrollo y la comunicación sobre gobernanza y Desarrollo de 2003 de la Comisión Europea. Sin embargo, el concepto de gobernanza ambiental ya había sido utilizado por el Banco Mundial en su informe de 1989 sobre África Subsahariana y más tarde en otros documentos como
Governance and development de 1992 (Castro-Buitrago, 2011).

12. Por ambiente debe entenderse agua, aire, suelo, propiedades físicas. Se puede ver como un proceso entre todo esto, los seres humanos y en general todos los seres vivos, como plantas y animales. También puede ser vista como la suma de las condiciones externas que afectan la vida, desarrollo y sobrevivencia de los organismos (Haque, 2017).

13. En Colombia uno de los principales cambios que se han dado con la Carta de 1991, es la apertura hacia una democracia participativa a través de las herramientas establecidas en el artículo 103, a saber, consulta popular, referendo, plebiscito, cabildo abierto, iniciativa legislativa, etc.

14. A pesar de los múltiples conceptos y nociones de gobernanza que han tratado de adaptarse a los procesos de regulación ambiental, el común denominador de tales definiciones está determinado en el énfasis dado a la participación ciudadana para la toma de decisiones de manera conjunta con los actores institucionales, así como el reconocimiento institucional de los espacios destinados para el desarrollo de tal integración (Castro Buitrago, 2017).

15. Propuesta desarrollada por los articulistas, y que se explicará a lo largo del presente texto

16. Incluso existen distintas tipologías de territorio según los niveles de gobernanza que se presenten. En primer lugar, se encuentran los territorios que han podido realizar una transformación productiva con cambios institucionales con niveles de participación y gobernanza, en segundo lugar, aquellas que han logrado una transformación productiva, pero con poca contribución a las economías locales. El tercer tipo con unas instituciones fuertes, pero con economías estancadas. El cuarto tipo de territorios son aquellos que tiene una desarticulación social y economías estancadas (Berdegué y Schejtman, 2007).

17. La Agencia Nacional de Minería no reporta información de títulos mineros respecto a los municipios de Paz del Río y Pisba.

18. Radicado 15238333300220180001601.

19. La definición de injusticia ambiental corresponde a la realizada por Shrader-Frechette (2002), expuesta supra.

20. Radicado 15238333300220180001601

\section{Referencias bibliográficas}

I. ALFIE COHEN, Miriam. Democracia deliberativa y gobernanza ambiental: iconceptos transversales de una nueva democracia ecológica? En: Sociológica. Septiembre-diciembre, 2013, 2013. vol. 28, no. 80, pp. 73-122. http://www.scielo.org.mx/scielo.php?script=sci arttext\&pid=S0187-01732013000300003\&lang $=p t$

2. ARCHILA, Mauricio. Colombia, Vida pasión y... de los movimientos sociales en Colombia. En: ARCHILA, Mauricio y PARDO, Mauricio (eds). Movimientos sociales, Estado y democracia en Colombia. Bogotá: Universidad Nacional de Colombia. 200 I pp. 16-47. http:// www.bdigital.unal.edu.co//497/2/0IPRELOI.pdf 
3. ARRIAGA LEGARDA, Alicia; PARDO BUENDÍA, Mercedes. Justicia ambiental. El estado de la cuestión. En: Revista Internacional de Sociología. Septiembre-diciembre, 20II. vol. 69, no. 3, pp. 627-648. https://doi.org// 0.3989/ris.2009.12.210

4. ASARA, Viviana; OTERO, lago, DEMARIA, Federico y CORBERA, Esteve. Socially sustainable degrowth as a social-ecological transformation: repoliticizing sustainability. En: Sustainability Science. Julio, 20I5. vol. I0, no. 3, pp. 375-384. https://doi.org/I0.1007/s I I625015-0321-9

5. AGENCIA NACIONAL DE HIDROCARBUROS - ANH. Respuesta derecho de petición $N^{\circ} 2018903042335$ I del 19 de septiembre de 2018 , reporte catastro y registro minero, corte $31 / 08 / 2018.2018$

6. AGENCIA NACIONAL DE HIDROCARBUROS -ANH. Respuesta derecho de petición $\mathrm{N}^{\circ}$ 201864/027559| del 13 de septiembre de 2018

7. AGENCIA NACIONAL DE MINERÍA-ANM. Boyacá avanza en Formalización Minera. 2015. https://www.anm.gov.co/?q=Boyaca avanza en Formalizacion Minera

8. AGENCIA NACIONAL DE MINERÍA-ANM. Informe de Gestión 2018. https://www.anm.gov.co/sites/default/files/informe_de gestion_segundo_trimestre_2018.pdf

9. BEBBINGTON, Anthony; ABRAMOVAY, Ricardo y CHIRIBOGA, Mamuel. Social Movements and the Dynamics of Rural Territorial Development in Latin America. En: World Development. Diciembre, 2008. vol. 36, no. 12, pp. 2874-2887. http://dx.doi.org//0.1016/j. worlddev.2007.11.017

10. BERDEGUÉ, Julio y SCHEJTMAN, Alexander. Desarrollo territorial rural en América Latina. Capitulo I. En: BENGOA José. Territorios Rurales Movimientos Sociales y Desarrollo Territorial Rural en América Latina. Santiago de Chile: RMSP - IDRC. 2007. pp. 9-3I. https://idl-bnc-idrc.dspacedirect.org/bitstream/handle//0625/26667/ IDL-26667.pdf

II. CASTRO-BUITRAGO, Erika. Aproximación al concepto de gobernanza en Colombia y algunos apuntes sobre su importancia en el derecho ambiental. En: Opinión Jurídica. Julio-diciembre, 20I I. vol. 166, edición especial, pp. 33-56. https://revistas.udem.edu.co/index. php/opinion/article/view/733

12. CASTRO-BUITRAGO, Erika. Derecho ambiental y gobernanza: la concertación como actuación informal de la administración. Medellín: Universidad de Medellín. 2017.456 p.

13. CASTRO Fabio, HOGENBOON, Barbara y BAUD, Michiel. Gobernanza ambiental en américa latina. CLACSO-ENGOV: Buenos Aires. 2015.376 p.

14. CERRILLO MARTíNEZ Agustí. La Gobernanza Hoy. En: CERRILLO MARTíNEZ Agustí La Gobernanza Hoy: 10 Textos de Referencia. España: Instituto Nacional de Administración Pública. Pp. II-36. https://dialnet.unirioja.es/servlet/articulo?codigo $=\mid 368084$

15. ECHAIDE, Javier. Demandas en el CIADI y el derecho humano al agua: ¿tratados de inversión vs. derechos humanos? En: International Law, Revista Colombiana de Derecho Internacional, Julio-Diciembre, 2017. no 31, pp. 8I-I |4. https://doi.org//0.1 I |44//Javeriana.il I4-31.dcdh

16. ESPINOSA, Angela. Autogobernanza, viabilidad y sostenibilidad: herramientas y aplicaciones. En: RODRÍGUEZ BECERRA Manuel y VÉLEZ María (Eds). Gobernanza y gerencia del desarrollo sostenible. Bogotá: Universidad de los Andes, 2018. pp. 2I I-242. www.jstor.org/ stable/ $10.7440 /$ j.ctvm $202 \mathrm{hb} .13$

17. ESPINOSA, Angela. Autogobernanza, viabilidad y sostenibilidad: 216 y VÉLEZ María. Gobernanza y gerencia del desarrollo sostenible. Bogotá: Universidad de los Andes, 2018. pp. 21 I-242.

18. GAMBA, Gloria; FUENTES, Hector y CONTRERAS, Leonardo. Efectos de la inversión extranjera en la actividad minera colombiana y de cuatro países de la región. En: Apuntes de CENES. Enero-junio, 20I2, vol. 3I, no. 53, pp. 5 I-79. https://revistas.uptc.edu.co/index.php/ cenes/article/view/4

19. GUDYNAS, Eduardo. Extracciones, extractivismos y extrahecciones. Un marco conceptual sobre la apropiación de recursos naturales. 2013. http://ambiental.net/wp-content/uploads/2015//2/ GudynasApropiacionExtractivismoExtraheccionesOdeD2013.pdf

20. GUDYNAS, Eduardo, Conflictos y extractivismos: conceptos, contenidos y dinamicas. En: Revista en Ciencias Sociales. 2014, no. 27-28, pp. 79-1/5. https://horizontescomunitarios.files.wordpress. com/2016/09/gudynas-conflictosextractrivismosconceptosdecs $\mid 4$. pdf

21. GUDYNAS, Eduardo. Extractivismos. Ecología, economía y política de un modo de entender el desarrollo y la Naturaleza. Cochabamba: CEDIB. 2015. 453. p. Disponible en: http://gudynas.com/wp-content/ uploads/GudynasExtractivismosEcologiaPoliticaBol5Anuncio.pdf

22. HAQUE, Mahfuzul. Environmental Governance. En: FARAZMAND, Alí. Global Encyclopedia of Public Administration, Public Policy, and Governance. New York: Springer. 2017. pp. 1-9. https://doi. org//0.1007/978-3-319-3/816-5

23. INSTITUTO ALEXANDER VON HUMBOLDT. Nueva Cartografía de los Páramos De Colombia Escala I:100.000. 2012. En: http:// www.humboldt.org.co/images/pdf/CartografiaParamos/2-GeneralHorizontal\%20Cartelas.pdf

24. LANDER, Edgardo. El Neoextractivismo como modelo de desarrollo en América Latina y sus contradicciones. Berlin: Fundación Heinrich Böll. 20I4. https://mx.boell.org/sites/default/files/edgardolander.pdf

25. MARÍN, Cesar; PARRA, Sandra. Bitácora de flora: Guía visual de plantas de páramos en Colombia. Bogotá: Instituto Alexander von Humboldt. 20I5. 356 p. http://www.humboldt.org.co/images/Fondo/ pdf/bitacorafloral.pdf

26. MARTÍNEZ CARAZO, Piedad. El método de estudio de caso: estrategia metodológica de la investigación científica. En: Pensamiento \& Gestión. Julio, 2016. no 20, pp. 165-193. https://www.redalyc.org/ pdf/646/64602005.pdf

27. MAYNTZ, Rene. Los Estados nacionales y la gobernanza global. En: Reforma y Democracia. Octubre, 2002. vol 44, no 24, pp. I-8. http:// hdl.handle.net/I /858/00-00IM-0000-00 I2-527F-4

28. MOLINA ORJUELA, Douglas. Gobernanza ambiental en Colombia: la acción estatal y de los movimientos sociales. En: Ambiente y Desarrollo. Enero-Junio, 2014, vol 18, no 34, p. 42-28. https://revistas. javeriana.edu.co/index.php/ambienteydesarrollo/article/view/9738

29. MOLINA ORJUELA, Douglas. y ROJAS Alexander. ¿Se está construyendo paz ambiental territorial con los pueblos ancestrales de Puerto Nariño, Amazonas-Colombia? Una mirada desde la ecología social y el buen vivir. En: Reflexión Política.Abril. 2019, vol 21, no 4I, p. I62-173. https://doi.org// 0.29375/0124078I.340I

30. PALACIOS-ALVARADO, Wlamyr; PRADA-BOTIA, Gaudy; LAGUADO-RAMÍREZ, Raquel. Glocalización: enfoque para la internacionalización comercial en Norte de Santander frente al nacionalismo económico de Estados Unidos. En: Revista Libre Empresa. Julio-Diciembre, 2017. vol. 14, no, 2, pp. 69-82. https://doi. org/l0.1804I/libemp.20I7.v14n2.28204

31. PAPA FRANCISCO. Laudato si. Sobre le cuidado de la casa Comun. Vaticano:Tipografia Vaticana. 20I5. $192 \mathrm{p}$. 
32. PÉREZ-RINCON, Mario Alejndro. Caracterizando las injusticias ambientales en Colombia: Estudio para II 5 casos de conflictos socioambientales. Valle del Cauca: MA-CA Univalle. 2016. https://censat. org/es/publicaciones/caracterizando-las-injusticias-ambientalesestudio-para-I|5-casos-de-conflictos-socioambientales-2

33. PÉREZ-RINCÓN, Mario; VARGAS-MORALES, Julieth y CRESPOMARÍN, Zulma. Trends in social metabolism and environmental conflicts in four Andean countries from 1970 to 2013. En: Sustainability Science. Noviembre, 2018. vol 13, no 3), pp. 635-648. https://doi.org//0.1007/s I 1625-017-0510-9

34. PREYER, Gerhard. Una interpretación de la globalización: un giro en la teoría sociológica. En: Revista mexicana de ciencias políticas y sociales. Junio-abril 2016. vol 6I, no 226, pp. 61-87. https://doi.org/10.1016/ Sol85-1918(16)30003-4

35. PORTILLO, Riascos. Extractivismo clásico y neoextractivismo, ¿dos tipos de extractivismos diferentes? I. En: Tendencias. Juliodiciembre, 20I4. vol I5, no 2, pp. II-29. https://doi.org//0.22267/ rtend. 141502.40

36. RAMÍREZ HERNÁNDEZ, Natalia; LEGUIZAMÓN ARIAS, Wilmer. La constitucionalización del desarrollo sostenible y sus efectos socio ambientales en el bosque alto andino de Boyacá. En: Principia luris. 2020. vol I6, no 32, pp. I 19- | 46. http://revistas.ustatunja.edu.co/index. php/piuris/article/view/|86|

37. RAMÍREZ HERNÁNDEZ, Natalia; LEGUIZAMÓN ARIAS, Wilmer. La naturaleza como víctima en la era del posacuerdo colombiano. En: El Ágora USB. 2020, no I, pp. 259-273. https://doi. org/10.21500/16578031.4296

38. RAMÍREZ HERNÁNDEZ Natalia; HERNÁNDEZ ROJAS Laura; LEGUIZAMÓN ARIAS Wilmer. Educación popular ambiental y resistencia campesina al extractivismo en el municipio de SamacáBoyacá. En: bol.redipe [Internet]. I de marzo de 2020, vol 9, no 3, p. 8-24. https://doi.org// 0.36260/rbr.v9i3.926

39. RIVERA OSPINA, David. Guía divulgativa de criterios para la delimitación de páramos de Colombia. Bogotá: Instituto Alexander von Humboldt, 201l. 70 p. http://www.humboldt.org.co/images/ Atlas\%20de\%20paramos/Guia_delimitacion_paramos.pdf

40. ROBERTSON Roland. Glocalization: Time-Space and HomogeneityHeterogenity. En FEATHERSTONE, Mike; LASH, Scott y ROBERTSON, Roland (eds.), Global Modernities. Londres: Sage, 1995. 25-44. https:// sk.sagepub.com/books/global-modernities/n2.xml

4I. SCHLOSBERG, David. Reconceiving environmental justice: Global movements and political theories. En: Environmental Politics. Junio, 2004, vol 13, no, 3, pp. 517-540. https://doi. org/l0.1080/0964401042000229025

42. SHRADER-FRECHETTE, Kristin. Enviromental Justice. Crating Equality, Reclaiming Democracy. New York: Oxford University Press, 2002. $269 \mathrm{p}$.

43. TEMPER, Leah; DEMARIA, Ferederico; SCHEIDEL, Aarnim; DEL BENE, Daniela y Martinez-Alier, Joan. The Global Environmental Justice Atlas (EJAtlas): ecological distribution conflicts as forces for sustainability. En: Sustainability Science. Abril, 2018. vol, 13, no, 3, pp. 573-584. https://doi.org/| 0.1007/s | |625-018-0563-4

44. TRUJILLO, Diana. La gobernanza en la gestión de la sostenibilidad y otros asuntos públicos. Sección ii de la gobernanza a la gerencia. En: RODRÍGUEZ BECERRA Manuel y VÉLEZ María. Gobernanza y gerencia del desarrollo sostenible. Bogotá: Universidad de los Andes, 2018. pp. |4I-178. www.jstor.org/stable// 0.7440/j.ctvm202hb.I

45. ULLOA, Astrid. El nativo ecológico. En: FALS BORDA Pardo y DELGADO, Álvaro (eds.), Movimientos sociales, Estado y democracia en Colombia. Bogotá: Universidad Nacional de Colombia, 200I. PP. 286-320. http://www.scielo.org.co/pdf/unih/n6l/n6/a I5.pdf

46. VALVERDE GARNICA, Álvaro. La gobernanza ambiental como enfoque para la cogestión adaptativa. En: Revista Integra Educativa. enero-junio, 2016. vol 9, no I, pp. I59-168. Disponible en http://www. scielo.org.bo/pdf/rieiii/v9n I/v9nI al0.pdf

47. VEGA PÉREZ, Álvarado Óstos, Gutiérrez Sánchez. El páramo de Pisba y la concesión minera: la problemática ambiental de Tasco (Boyacá). En: Revista Academia \& Derecho, 20I7. año 8, n ${ }^{\circ}$ 15, pp. 5I-84. https:// doi.org//0.1804I/22/5-8944/academia. I5.4333

48. WWF-Colombia. Colombia Viva. Un país mega diverso de cara al futuro Informe 2017. Cali:WWF-Colombia. 2017. 162 p. https:// d2ouvy 59 p0dg6k.cloudfront.net/downloads/colombia_viva informe 2017 I.pdf

Normatividad

I. COLOMBIA. AUTORIDAD NACIONAL DE LICENCIAS AMBIENTALES (ANLA). Resolución $N^{\circ} 929$ del ocho (8) de agosto del año 2017.

2. COLOMBIA. AUTORIDAD NACIONAL DE LICENCIAS AMBIENTALES (ANLA). Auto $\mathrm{N}^{\circ} 78$ del 17 de enero de 2012

3. COLOMBIA. CONGRESO DE LA REPÚBLICA. Ley 99. (22, diciembre, 1993). Por la cual se crea el Ministerio del Medio Ambiente, se reordena el Sector Público encargado de la gestión y conservación del medio ambiente y los recursos naturales renovables, se organiza el Sistema Nacional Ambiental, SINA y se dictan otras disposiciones. Diario oficial. Bogotá, D.C., 1993. No. 41.146. p- I-59. http://www. secretariasenado.gov.co/senado/basedoc/ley 0099 1993.html

4. COLOMBIA. MINISTERIO DE AMBIENTE Y DESARROLLO TERRITORIAL. Resolución 2000 del 16 de octubre de 2009. http:// portal.anla.gov.co/sites/default/files/res_2000_161009.pdf

5. COLOMBIA, MINISTERIO DE AMBIENTE, VIVIENDA Y DESARROLLO TERRITORIAL. Resolución 553 del 16 de marzo de 2010. https://www.redjurista.com/Documents/resolucion_553_ de_2010_cne_-_consejo_nacional_electoral.aspx\#l

\section{Jurisprudencia}

I. TRIBUNAL ADMINISTRATIVO DE BOYACÁ. Sentencia de tutela radicado 152383333002201800016 0I. M. P. Clara Elisa Cifuentes. 2018. http://files.harmonywithnatureun.org/uploads/upload731.pdf

2. CORTE CONSTITUCIONAL. Sentencia de tutela T-34I de 20I6. M.P. Gabriel Eduardo Mendoza Martelos. https://www.corteconstitucional. gov.co/relatoria/2016/T-341-16.htm

3. CORTE CONSTITUCIONAL. Sentencia de tutela T-36I de 2017. MP. M.P. Alberto Rojas Ríos. https://www.corteconstitucional.gov.co/ relatoria/2017/t-361-17.htm

4. PORTILLO, Riascos. Extractivismo clásico y neoextractivismo, ¿dos tipos de extractivismos diferentes? I. En: Tendencias. Julio-diciembre, 20I4. vol I5, no 2, pp. II-29.

5. RAMÍREZ HERNÁNDEZ, Natalia;LEGUIZAMÓN ARIAS, Wilmer. La constitucionalización del desarrollo sostenible y sus efectos socio ambientales en el bosque alto andino de Boyacá. En: Principia luris. 2020. vol 16, no 32, pp. II9-146.

6. RAMÍREZ HERNÁNDEZ, Natalia; LEGUIZAMÓN ARIAS, Wilmer. La naturaleza como víctima en la era del posacuerdo colombiano. En: El Ágora USB. 2020, no I, pp. 259-273. https://doi. org/10.21500/16578031.4296 
7. RAMÍREZ HERNÁNDEZ Natalia; HERNÁNDEZ ROJAS Laura; LEGUIZAMÓN ARIAS Wilmer. Educación popular ambiental y resistencia campesina al extractivismo en el municipio de SamacáBoyacá. En: bol.redipe [Internet]. I de marzo de 2020, vol 9, no 3, p. 8-24. https://doi.org//0.36260/rbr.v9i3.926

8. RIVERA OSPINA, David. Guía divulgativa de criterios para la delimitación de páramos de Colombia. Bogotá: Instituto Alexander von Humboldt, 20II.70 p.

9. ROBERTSON Roland. Glocalization: Time-Space and HomogeneityHeterogenity. En: FEATHERSTONE, Mike;

10. LASH, Scott y ROBERTSON, Roland (eds.), Global Modernities. Londres: Sage, 1995. 25-44. ç

II. SCHLOSBERG, David. Reconceiving environmental justice: Global movements and political theories. En: Environmental Politics. Junio, 2004, vol I3, no, 3, pp. 5 I7-540. https://doi.org//0.1080/09644010420 00229025.

12. SHRADER-FRECHETTE, Kristin. Enviromental Justice. Crating Equality, Reclaiming Democracy. New York: Oxford University Press, 2002. $269 \mathrm{p}$.

13. TEMPER, Leah; DEMARIA, Ferederico; SCHEIDEL, Aarnim; DEL BENE, Daniela y Martinez-Alier, Joan. The Global Environmental Justice Atlas (EJAtlas): ecological distribution conflicts as forces for sustainability. En: Sustainability Science. Abril, 2018. vol, 13, no, 3, pp. 573-584. https://doi.org/10.1007/s | |625-018-0563-4

14. TRUJILLO, Diana. La gobernanza en la gestión de la sostenibilidad y otros asuntos públicos. En: RODRÍGUEZ BECERRA Manuel y VÉLEZ María. Gobernanza y gerencia del desarrollo sostenible. Bogotá: Universidad de los Andes, 2018. pp. I4I-I78.

15. ULLOA, Astrid. El nativo ecológico. En: FALS BORDA Pardo y DELGADO, Álvaro (eds.), Movimientos sociales, Estado y democracia en Colombia. Bogotá: Universidad Nacional de Colombia, 200I. pP. 286-320.

16. VALVERDE GARNICA, Álvaro. La gobernanza ambiental como enfoque para la cogestión adaptativa. En: Revista Integra Educativa. enero-junio, 2016. vol 9, no I, pp. 159-168. Disponible en: http:// www.scielo.org.bo/scielo.php?script=sci_arttext\&pid=SI 997 404320 I6000 I 000 I 0\&lang=pt\%5Cnhttp://www.scielo.org.bo/pdf/ rieiii/v9nI/v9nI_al0.pdf

17. VEGA PÉREZ, Álvarado Óstos, Gutiérrez Sánchez. El páramo de Pisba y la concesión minera: la problemática ambiental de Tasco (Boyacá). En: Revista Academia \& Derecho, 2017. año 8, n 15, pp. 51 84. http://www.unilibrecucuta.edu.co/ojs/index.php/derecho/article/ view/230/277

18. WWF-Colombia. Colombia Viva. Un país mega diverso de cara al futuro Informe 2017. Cali:WWF-Colombia. 2017. 162 p. Disponible en: https://d2ouvy59p0dg6k.cloudfront.net/downloads/colombia viva_informe_2017_l.pdf 